\title{
Effect of Body Posture on Lung Ventilation and Oxygenation During Carbon Dioxide Pneumoperitoneum in Rabbit
}

\author{
Iulia MELEGA ${ }^{1 *}$, Cosmina DEJESCU ${ }^{1}$, Mădălina DRAGOMIR ${ }^{1}$, Cecilia DANCIU ${ }^{1}$, \\ Florica MATEI ${ }^{2}$, Liviu OANA ${ }^{1}$, Cosmin PESTEAN ${ }^{1 * *}$
}

\author{
${ }^{1}$ Faculty of Veterinary Medicine, University of Agricultural Science and Veterinary Medicine Cluj-Napoca, Mănăștur \\ street 3-5, Cluj-Napoca, 400372, Romania \\ ${ }^{2}$ Faculty of Horticulture, University of Agricultural Science and Veterinary Medicine Cluj-Napoca, Mănăștur street 3-5, \\ Cluj-Napoca, 400372, Romania \\ * Corresponding author: Iulia MELEGA email: melega.iulia@gmail.com \\ **Same contribution as the first author
}

RESEARCH ARTICLE

\begin{abstract}
This study was conducted to investigate the influence of body position on respiratory compliance and oxygenation during iatrogenic pneumoperitoneum in the rabbit. The peak inspiratory pressure, dynamic compliance, static compliance and arterial gas parameters were calculated and measured $10 \mathrm{~min}$ before and $30 \mathrm{~min}$ after the creation of pneumoperitoneum with the patient in the horizontal position, $30 \mathrm{~min}$ after placing the patient in the Trendelenburg position and $30 \mathrm{~min}$ after placing the patient in the reversed Trendelenburg position. Following the creation of pneumoperitoneum and Trendelenburg positioning, there was a significant increase in peak inspiratory pressure while dynamic and static respiratory compliance decreased. Similarly, arterial oxygenation increased during Trendelenburg position while arterial carbon pressure remained within limits during all positions. Overall, the reverse Trendelenburg position did not improve ventilation, neither the oxygenation. However, this position showed to be more appropriate because may reduce the risk of lung injury associated with high-pressure ventilation during pneumoperitoneum.
\end{abstract}

Keywords: Trendelenburg; pneumoperitoneum; ventilation.

Received: 15 September 2020

Accepted: 11 January 2021

Published: 14 May 2021

DOI:

10.15835/buasvmcn-vm:2020.0028

\section{INTRODUCTION}

In recent years' surgical procedures using laparoscopic techniques have been performed more frequently in small animals, including rabbits. Studies have demonstrated that these techniques are associated with less pain and an overall better outcome in comparison with open surgical methods (Mama and de Rezende, 2015). However, for the anaesthesiologist, laparoscopic surgery represents a challenge. The most prominent factors affecting the patient stability are related to insufflation of gas inside the peritoneal cavity, increased abdominal pressure and positioning of the patient (Srivastava and Niranjan, 2010). During laparoscopic surgery, carbon dioxide (CO2) is introduced into the peritoneum, to provide a good visibility of internal structures and workspace. High abdominal pressure represents an increased ventilation load due to a cranial shift of the diaphragm, favouring lung collapse and decreasing chest wall compliance and functional residual capacity (FRC) (Hedestierna and Rothen, 2012). In human patients, recent studies have focused on new methods for improving surgical workspace, such as patient's body position. In clinical situations, patients are positioned in the Trendelenburg (head-down) or reversed Trendelenburg (head-up) positions, to expose the organ of interest (Mulier et al., 2009). However, the effects of surgical manoeuvres accompanying laparoscopic surgery, summed to body position may either exacerbate or alleviate the pneumoperitoneum impact on respiratory mechanics and oxygenation. The 
physiological effects of pneumoperitoneum may lead the clinician to question whether a reversed Trendelenburg position may be beneficial during laparoscopic surgery in rabbit patient. Studies have shown that when shifting from supine to headdown position dynamic lung compliance decreases while the airway pressure increases, which results in further changes in the respiratory system (Fahy et al., 1996). On this basis, it was hypothesised that a head-up position should improve respiratory homogeneity, and subsequent gas exchange. To address this question, the present study investigated the mechanical properties of the total respiratory system and gas exchange in the anesthetised rabbit in the horizontal, Trendelenburg and reversed Trendelenburg positions during experimentally induced pneumoperitoneum.

\section{MATERIALS AND METHODS}

\section{Animals}

Five seven-month old male rabbits were included in this prospective study. All animals were considered healthy based on the clinical evaluation performed before procedures. The experimental procedure was approved by the Comity for Bioethics and Research Ethics of University of Agricultural Sciences and Veterinary Medicine Cluj-Napoca (aut. no 204/12.03.2020) and complied with the European Directive 22.09.2010/63/EU, and Romanian national law 43/2014 for protection of animals used for scientific purposes.

\section{Anaesthesia protocol}

General anaesthesia was induced with a combination of xylazine $5 \mathrm{mg} / \mathrm{kg}$ (Xylazin Bio 2\%, Bioveta, Ivanovice na Hane, Czech Republic) and ketamine $35 \mathrm{mg} / \mathrm{kg}$ (Narkamon Bio $100 \mathrm{mg} / \mathrm{ml}$, Bioveta, Ivanovice na Hane, Czech Republic) administered in the epaxial muscle. After ear pinch reflex loss, the pinnae of the ears were clipped and aseptically prepared for arterial and venous catheter placement. To facilitate tracheal intubation, lidocaine $2 \%$ (Xilina $20 \mathrm{mg} / \mathrm{ml}$, Zentiva, Bucharest, Romania) was applied topically to the larynx. The rabbits were intubated blindly in the supine position or under laryngoscope guidance, using a 3.0 cuffed endotracheal tube. Once the airway was secured, the patients were connected to a rebreathing circuit and maintained on isoflurane (Isoflutek, $1000 \mathrm{mg} / \mathrm{g}$, Laboratorios Karizoo, Barcelona, Spain) at a 1.5\% expired fraction of isoflurne in $100 \%$ oxygen (FiO2). During experimental procedure, animals received mechanical ventilation using volume control module with a Dräger Fabius Plus XL anaesthetic machine (Dräger, Lübeck, Germany). Rocuronium $0.5 \mathrm{mg} / \mathrm{kg}$ (Rocuronium Kabi $10 \mathrm{mg} / \mathrm{ml}$, Fresenius, Poland) was administered to ensure complete muscle relaxation, and was maintained with subsequent boluses of 0.1 $\mathrm{mg} / \mathrm{kg}$, as needed. Standard monitoring included continuous electrocardiography, invasive blood pressure, peripheral oxygen saturation $\left(\mathrm{SpO}_{2}\right)$, end-tidal carbon dioxide concentration $\left(\mathrm{E}_{\mathrm{t}} \mathrm{CO}_{2}\right)$ and body temperature, all variables being recorded every 10 min. Ventilator parameters were set to deliver a target tidal volume (Vt) of $7 \mathrm{ml} / \mathrm{kg}$ with a peak inspiratory pressure (PIP) not exceeding $20 \mathrm{~cm} \mathrm{H} 2 \mathrm{O}$, inspiratory to expiratory ratio 1:2 and a positive-end-expiratory pressure of $3 \mathrm{~cm} \mathrm{H} 2 \mathrm{O}$, throughout the procedure. The respiratory rate was adjusted to maintain an EtCO2 between 35-45 mmHg. Gas measurements in the breathing circuit were analysed using Scio Gas Measurement Module (Scio Four Dräger, Lübeck, Germany). Fluid therapy with Ringer's solution (Ringer B Braun, B. Braun Pharmaceuticals, Timisoara, Romania) was administered by fluid pump at a rate of 10 $\mathrm{ml} / \mathrm{kg} / \mathrm{hr}$. The volume of blood collected for analysis was replaced with an equal volume of a colloid solution $(6 \%$ Hemohes 200/0.5 B. Braun Pharmaceuticals, Timisoara, Romania) to maintain hemodynamic stability. Thermal support was provided with a forced-air warming device (Bair Hugger Warmer Series 505, Augustine Medical, South Africa). At the end of the procedure, each rabbit received meloxicam $1 \mathrm{mg} / \mathrm{kg}$ (Melovem $5 \mathrm{mg} / \mathrm{ml}$, Dopharma, Romania) for pain control.

\section{Procedure protocol}

All rabbits were placed in an X-ray positioner (Pawsitioner, Avail Concepts, LLC, USA) over the surgical table. After 10 minutes of stabilization under mechanical ventilation, pneumoperitoneum was established by insufflation of carbon dioxide $\left(\mathrm{CO}_{2}\right)$ into the abdomen, at an abdominal pressure of $8 \mathrm{mmHg}$. Thereafter, the body positions were investigated, in the following order: horizontal position (HP), Trendelenburg position (TP) with an angle of $15^{\circ}$ and Reversed Trendelenburg (RTP) with an angle of $15^{\circ}$. A protractor Smartphone application was used to measure the angles (Protractor app v1.05). Between positions changes, 3 ventilations at 1.5-2 times Vt were performed over 10 minutes, with the patient in the HP.

Blood gas variables were considered to evaluate the efficacy of pulmonary gas exchange, and were recorded at 4 timepoints: $10 \mathrm{~min}$ after induction of anaesthesia (baseline); $30 \mathrm{~min}$ after pneumoperitoneum in HP; $30 \mathrm{~min}$ after pneumoperitoneum in TP and $30 \mathrm{~min}$ after pneumoperitoneum in RTP. Arterial blood was collected from the arterial catheter using a $2 \mathrm{ml}$ pre-heparinized syringe (Luer Slip Blood Gas Sampling system, Numbrecht Germany) and analysed within 3 min with a point-of-care blood gas analyzer (Stat Profile Prime Plus ${ }^{\circledR}$ VET Critical Care Analyzer, Nova Biomedical). After collection, air bubbles were expelled and the syringe was covered with a plastic cap. The blood was analysed for $\mathrm{pH}$, partial pressure of arterial oxygen $(\mathrm{PaO} 2)$, partial pressure arterial carbon dioxide $(\mathrm{PaCO} 2)$ and standard bicarbonate (SBC). The alveolar to arterial oxygen difference $(\mathrm{A}-\mathrm{aDO} 2)$ and the ratio between arterial oxygen partial pressure and inspired oxygen concentration $(\mathrm{PaO} 2 / \mathrm{FiO} 2)$ were calculated using the integrated analyser software, whereas the arterial-to-end-tidal carbon dioxide tension $(\mathrm{P}(\mathrm{a}-\mathrm{ET}) \mathrm{CO} 2)$ was calculated with each arterial blood analysis and EtCO2 reading. For assessment of respiratory mechanics, the Vt, PIP, plateau airway pressure (Plat), PEEP were recorded by the ventilator module and displayed in real time. Dynamic lung-thorax compliance (CDYN) was calculated by dividing Vt by the difference between PIP and PEEP whereas static compliance (CSTAT) was measured by dividing Vt by the difference 
between Plat and PEEP. Measurements of the respiratory mechanics were taken at the same time intervals as the arterial blood gas analysis.

\section{Statistical analysis}

Statistical analysis was performed using SPSS version 20 software (SPSS Inc, Chicago, IL, USA). Measurement changes were analysed by comparing data between positions and with baseline values. Descriptive analysis (means, standard deviation (SD), medians and interquartile range) were calculated. To assume Gaussian distribution, normality was checked by Shapiro-Wilks test. Normally distributed data was compared using repeated measure ANOVA and Wilk's Lambda tests. For non-parametric distributed data, the Friedman two-way analysis of variance by ranks was performed. Differences between the average ranks were considered statistically significant al level of $p<0.05$. The differences between pairs was analysed after applying the Bonferroni correction for the number of comparisons, considering a level of significance of adjusted $\mathrm{p}<0.05$.

\section{RESULTS AND DISCUSSIONS}

All 5 rabbits (mean body weight $3.52 \pm 0.305 \mathrm{~kg}$ ) were successfully studied. Tracheal intubation was performed blindly in 4 rabbits and under laryngoscope guidance in 1 rabbit. One patient required rocuronium supplementation during the experiment. No complication consequent to either anesthesia or pneumoperitoneum was reported.

\section{Hemodynamic stability}

The haemodynamic variables are listed in Table 1. The heart rate increased after creation of pneumoperitoneum, showing a significant difference during TP as compared with baseline. Although not significant, positioning in the RTP caused a decrease in the mean arterial blood pressure, 4 animals becoming hypotensive, requiring an increment in fluid therapy.

\section{Analysis of arterial blood gas}

The body position did not differ in terms of the changes in blood $\mathrm{pH}, \mathrm{P}_{\mathrm{a}} \mathrm{CO}_{2}, \mathrm{~A}-\mathrm{aDO}$ and $\mathrm{SBC}$. The Friedman-twoway analysis of variance by ranks showed statistically significant difference between baseline and TP with respect to $\mathrm{P}_{\mathrm{a}} \mathrm{O}_{2}$ and $\mathrm{PO}_{2} / \mathrm{FiO}_{2}$ (Table 1). In the case of $\mathrm{P}_{(\mathrm{a}-\mathrm{Et})} \mathrm{CO}_{2}$ gradient, measurements showed negative values, but without significant differences between positions.

\section{Respiratory mechanics}

The Vt was maintained constant throughout the experimental procedure; therefore, the PIP had to be increased after insufflation of $\mathrm{CO}_{2}$. Trendelenburg positioning required a further increase in PIP up to almost twofold ( $\left.\mathrm{p}=0.01\right)$ but returned to baseline values after removal of peritoneal $\mathrm{CO}_{2}$ and $\mathrm{HP}$ position (Figure 1). The mean $\pm \mathrm{SD}$ values for $\mathrm{C}_{\mathrm{DYN}}$ and $\mathrm{C}_{\mathrm{STAT}}$ in the mechanically ventilated rabbits were $3.150 \pm 0.674 \mathrm{ml} / \mathrm{cm} \mathrm{H}_{2} \mathrm{O}$ and $3.32 \pm 0.773 \mathrm{ml} / \mathrm{cm} \mathrm{H}_{2} \mathrm{O}$, decreasing by almost $50 \%$, after gas insufflation. There were no significant differences in $\mathrm{C}_{\mathrm{DYN}}$ values between positions; however, the animals in TP showed the lowest compliance as compared with baseline $(\mathrm{p}=0.026)$. Following removal of peritoneal $\mathrm{CO}_{2}, \mathrm{C}_{\mathrm{DYN}}$ returned to baseline values (Figure 2). As regard to $\mathrm{C}_{\mathrm{STAT}}$, the repeated-measure ANOVA test demonstrated significant differences between baseline and $\mathrm{HP}(\mathrm{p}=0.014)$ and TP $(\mathrm{p}=0.028)$. Finally, $\mathrm{C}_{\mathrm{STAT}}$, after removal of $\mathrm{CO}_{2}$ gas and return to the supine position, was slightly lower than the baseline values (Figure 3 ).

Table 1. Haemodynamic, respiratory and blood gas parameters in anesthetised rabbits

\begin{tabular}{|c|c|c|c|c|c|}
\hline & $\begin{array}{c}\text { Baseline } \\
\mathrm{N}=5\end{array}$ & $\begin{array}{l}\text { HP } \\
N=5\end{array}$ & $\begin{array}{c}\text { TP } \\
N=5\end{array}$ & $\begin{array}{l}\text { RTP } \\
\text { N=5 }\end{array}$ & $\begin{array}{c}\text { Adjusted P } \\
\text { value }\end{array}$ \\
\hline HR (bpm) & $168(168 ; 175)^{\mathrm{a}}$ & $215 \pm 0.985$ & $193 \pm 17.152 *$ & $188.4 \pm 11.415$ & 0.004 \\
\hline MAP (mmHg) & 65 & $60(55 ; 60)^{\mathrm{a}}$ & $72 \pm 12.042$ & $55.8 \pm 12.872$ & - \\
\hline RR (breath) & 25 & 25 & 25 & 25 & \\
\hline $\mathrm{E}_{t} \mathrm{CO}_{2}(\mathrm{mmHg})$ & $39.6 \pm 5.595$ & $40.4 \pm 4.561$ & $42.2 \pm 1.923$ & $43.4 \pm 2.881$ & - \\
\hline pH & $7.433 \pm 0.092$ & $7.43 \pm 0.553$ & $7.432 \pm 0.47$ & $7.424(7.407 ; 7.425)$ & - \\
\hline $\mathrm{P}_{\mathrm{a}} \mathrm{CO}_{2}(\mathrm{mmHg})$ & $36.4 \pm 8.203$ & $39.5(38.9 ; 40.2)^{\mathrm{a}}$ & $40.4(40.3 ; 41)^{\mathrm{a}}$ & $43.06 \pm 3.013$ & - \\
\hline $\mathrm{P}_{\mathrm{a}} \mathrm{O}_{2}(\mathrm{mmHg})$ & $301.480 \pm 91$ & $380 \pm 70.39$ & $403(402 ; 415)^{\mathrm{a} *}$ & $385.7 \pm 24.49$ & 0.042 \\
\hline SBC (mmol/L) & $26 \pm 4.842$ & $28.180 \pm 4.120$ & $28.380 \pm 3.942$ & $26.940 \pm 2.051$ & - \\
\hline $\mathrm{A}-\mathrm{aDO}_{2}(\mathrm{mmHg})$ & $324.76 \pm 100$ & $261(238 ; 297)^{\mathrm{a}}$ & $217(215 ; 223)^{\mathrm{a}}$ & $240.480 \pm 23.148$ & - \\
\hline $\mathrm{PO}_{2} / \mathrm{FiO}_{2}(\mathrm{mmHg})$ & $301.28 \pm 91.161$ & $379.84 \pm 70.4$ & $403.7(402 ; 415)^{\mathrm{a} *}$ & $385.7 \pm 24.49$ & 0.042 \\
\hline $\mathrm{P}_{(\mathrm{a}-\mathrm{Et})} \mathrm{CO}_{2}(\mathrm{mmHg})$ & $-3.8 \pm 4.425$ & $1.38 \pm 4.955$ & $-0.46 \pm 3.637$ & $-0.34 \pm 3.954$ & - \\
\hline
\end{tabular}

$\mathrm{HR}$ indicates heart rate; MAP, mean arterial pressure; $\mathrm{RR}$, respiratory rate; $\mathrm{MV}$, minute volume; $\mathrm{E}_{\mathrm{t}} \mathrm{CO}_{2}$, end-tidal carbon dioxide; $\mathrm{P}_{(\mathrm{a}-}$ ${ }_{E t)} \mathrm{CO}_{2}$, arterial to end tidal carbon dioxide gradient; $\mathrm{P}_{\mathrm{a}} \mathrm{CO}_{2}$, partial pressure of arterial carbon dioxide; $\mathrm{P}_{\mathrm{a}} \mathrm{O}_{2}$, partial pressure of arterial oxygen; SBC, standard bicarbonate, $\mathrm{A}-\mathrm{aDO}_{2}$, alveolar arterial oxygen gradient, $\mathrm{PO}_{2} / \mathrm{FiO}_{2}$, ratio between arterial oxygen partial pressure and inspired oxygen concentration; HP, horizontal position; TP, Trendelenburg position; RTP, reverse Trendelenburg position; a, median and IQR. 


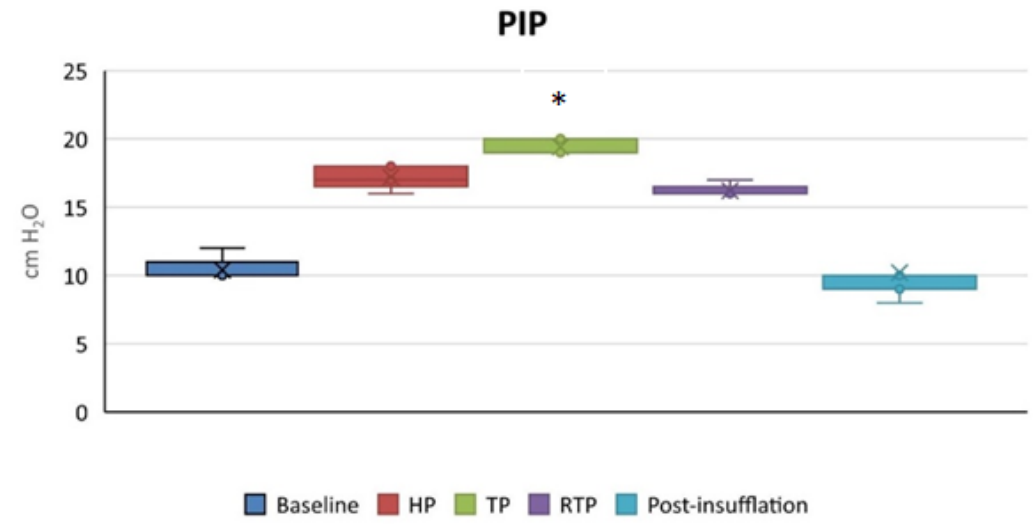

Figure 1. Comparison of peak inspiratory pressure measured $10 \mathrm{~min}$ after induction of anesthesia (baseline), $30 \mathrm{~min}$ after $\mathrm{CO} 2$ gas insufflation with the patient in the horizontal position (HP), $30 \mathrm{~min}$ after placing the patient in the Trendelenburg position (TP), 30 min after placing the patient in the reversed Trendelenburg position (RTP) and after deflating the abdomen. $* \mathrm{p}<0.05$ as compared with baseline.

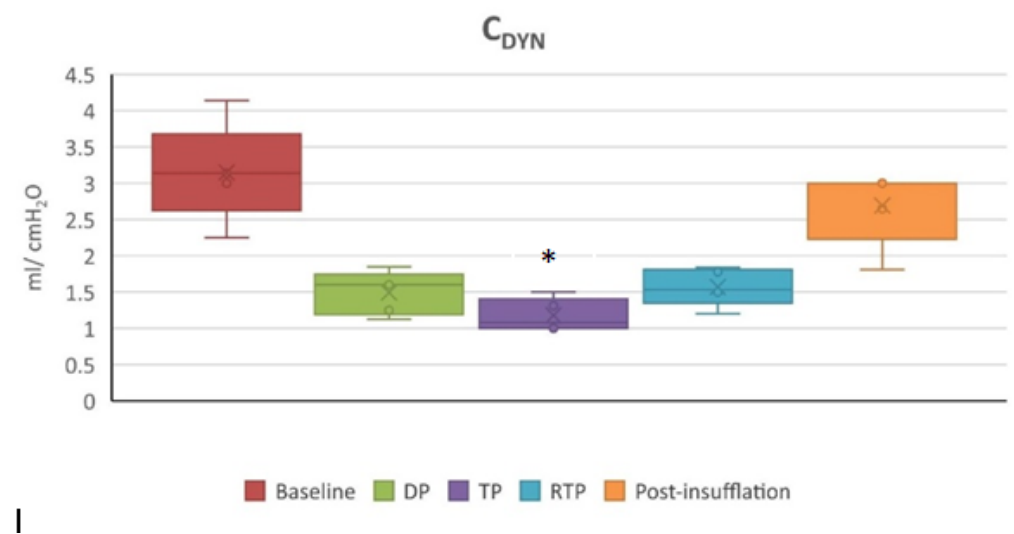

Figure 2. Comparison of dynamic compliance measured $10 \mathrm{~min}$ after induction of anesthesia (baseline), 30 min after $\mathrm{CO} 2$ gas insufflation with the patient in the horizontal position (HP), 30 min after placing the patient in the Trendelenburg position (TP), 30 min after placing the patient in the reversed Trendelenburg position (RTP) and after deflating the abdomen. * $\mathrm{p}<0.05$ as compared with baseline.

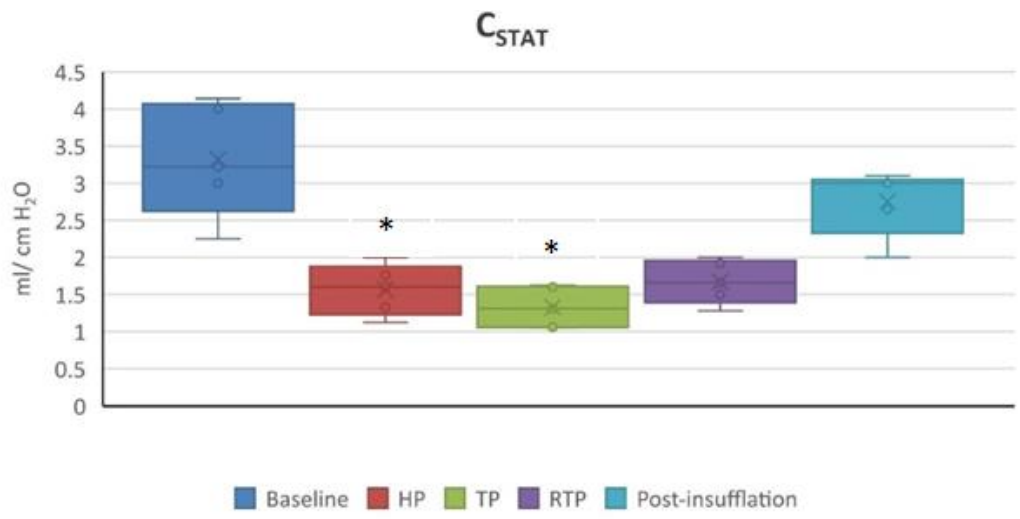

Figure 3. Comparison of static compliance measured $10 \mathrm{~min}$ after induction of anaesthesia (baseline), 30 min after $\mathrm{CO}_{2}$ gas insufflation with the patient in the horizontal position (HP), 30 min after placing the patient in the Trendelenburg position (TP), 30 min after placing the patient in the reversed Trendelenburg position (RTP) and after deflating the abdomen. ${ }^{*} \mathrm{p}<0.05$ as compared with baseline.

The findings of the present study indicate that iatrogenic pneumoperitoneum results in decreased dynamic and static respiratory compliance and elevation of peak inspiratory pressure, regardless of the body position. These changes were not 
associated with a significant improvement in gas exchange, with the exception in TP, as was shown by arterial blood gas analysis. Besides, in all positions, hypercarbia associated with peritoneal carbon dioxide insufflation was effectively prevented.

Compliance is defined as the ratio between the change in volume and the change in pressure. This measurement is used frequently to assess the pulmonary status and, depending on the method of measurement, it is described as static and dynamic. Measurement of static compliance is preferable over dynamic to evaluate lung parenchymal changes because it reflects compliance without airway resistance (Hess, 2014). In the present study both dynamic and static compliance decreased once pneumoperitoneum reached a pressure of $8 \mathrm{mmHg}$. Because $\mathrm{Vt}$ was maintained constant during mechanical ventilation, the PIP had to be increased, whereas C STAT decreased. As suggested by Srivastava and Niranjan (2015), these changes occurred most probably due to a limitation of diaphragm movement and decreased inflation of the lungs. Trendelenburg positioning exacerbated further the pneumoperitoneum-related displacement of the diaphragm; therefore, a greater reduction in $\mathrm{C}_{\text {STAT }}$ was recognized when the head-down position was applied simultaneously to pneumoperitoneum. Previous studies have shown that altered postures can affect respiratory compliance even in the patient without pneumoperitoneum (Davidson et al., 1966). Respiratory compromise is the major complication in the anaesthetized rabbit and is related to the small thoracic size compared with the abdominal cavity. In contrast to other species, in rabbit, the diaphragm muscle has a larger contribution in breathing function, whereas the chest excursions are limited (Eatwell, 2014). This is especially important during anaesthesia, as most anaesthetic drugs reduce muscle tone and impair ventilation homogeneity. Such negative effects are further emphasized in the head-down position, secondary to the gravitational forces of the abdominal content on the diaphragm and to the pulmonary blood volume elevation which reduces lung elastance (Davidson et al., 1966). Manner et al. (1998) have demonstrated a reduction of $\mathrm{C}_{\text {STAT }}$ of $17 \%$ in children with a head-down position, with an additional decrease of $10 \%$ after gas insufflation. The differences in chest wall conFigureuration and higher abdominal compartment in rabbits may account the greater reduction in compliance observed in the present study.

The change in the RTP corresponded to a slight improvement in diaphragmatic function as was shown by the increased respiratory compliance and decreased PIP; however, it was not statistically significant as compared with HP and TP. Our findings coincided with the study by Casati et al. (2000) on thoracic and lung compliance during laparoscopic gastric banding, in which RTP had no beneficial effects. It can be suggested that pneumoperitoneum alter respiratory mechanics to such an extent that further changes, like patient positioning, cannot affect in a positive manner respiratory dynamics. This could explain why the changes in lung function remained more or less constant throughout the experimental procedure. Nevertheless, a lower PIP could reduce the risk of ventilator-induced lung injury, a common complication associated with mechanical ventilation. A recent study by Walesa et al. (2018) on ventilation strategies in rabbit demonstrated that even a protective ventilation strategy with low PIP and moderate PEEP can be associated with lung oedema and structural changes in the alveoli. In another study conducted by Hua et al. (2013) in anesthetised rabbits, a moderate $\mathrm{PIP}\left(18 \mathrm{cmH}_{2} \mathrm{O}\right) \mathrm{was}$ associated with the mildest lung injury and homogenous ventilation; the lowest PIP $\left(10 \mathrm{cmH}_{2} \mathrm{O}\right)$ produced atelectasis whereas the highest level of PIP $\left(25 \mathrm{~cm} \mathrm{H}_{2} \mathrm{O}\right)$ caused barotrauma. Although in the present study PIP did not vary significantly between positions, and although we did not evaluate the impact of ventilation on lung integrity, from the clinical point of view, RTP position could be accounted for a protective ventilation strategy during laparoscopy surgery.

Reduced compliance impairs adequate pulmonary gas exchange, predisposing the patients to hypercarbia and hypoxemia. Moreover, pneumoperitoneum increases the chances for atelectasis development (Strang et al., 2010). To minimize this complication, ventilation with PEEP was used and recruitment manoeuvres were performed to reopen collapsed alveoli and to restore impaired gas exchange (Valenza et al., 2010). In addition, the rabbits were ventilated for short periods, which might not have been long enough for the development of significant atelectasis. These techniques demonstrated to be efficient in maintaining proper gas exchange, as all animals remained normocapnic during all body postures. There is a lack of consensus regarding the timing and the frequency of application of sigh ventilations in the literature. The authors in this study chose an interval of 30 minutes that coincided with body position change, to limit the impact of previous position on the measurements at subsequent positions. The study conducted by Makwana et al. (2014) on patients undergoing laparoscopic surgery has shown that $\mathrm{E}_{\mathrm{t}} \mathrm{CO}_{2}$ increases during carbon dioxide pneumoperitoneum, in close agreement with $\mathrm{PaCO} 2$. In our patients, $\mathrm{E}_{\mathrm{t}} \mathrm{CO}_{2}$ remained within limits; moreover, it exceeded the sampled $\mathrm{P}_{\mathrm{a}} \mathrm{CO}_{2}$. Negative arterial to end-tidal carbon dioxide gradient has been reported previously in infant patients, and it is associated with mechanical ventilation with low ratio of tidal volume to deadspace, high $\mathrm{CO}_{2}$ sampling rates and high ventilatory rates with high fresh gas flows (Ickx et al., 2015). In the present study, the controlled ventilation mode was set to deliver a relative small Vt with PEEP in order to reduce the repeated closure and opening of terminal alveoli leading to shear stress. On the other side, the respiratory rate was lower in comparison with the normal rate for the anaesthetized rabbit, which 
could have led the gas emptied from alveoli to remain in the airways, thus explaining the $\mathrm{E}_{\mathrm{t}} \mathrm{CO}_{2}$ values (Fletcher and Jonson, 1984).

In our patients, arterial oxygenation did not deteriorate; conversely, it increased after pneumoperitoneum induction, with significant difference in TP. In addition, a decrease in $\mathrm{A}-\mathrm{aDO}_{2}$ was also noted in patients during $\mathrm{TP}$, although not significant. The higher levels of $\mathrm{P}_{a} \mathrm{O}_{2}$ and $\mathrm{PO}_{2} / \mathrm{FiO}_{2}$ were highly suggestive for a lower pulmonary shunt in comparison to other postures (Petersson and Glenny, 2014). The authors attributed the changes to higher ventilation demands. There are papers demonstrating increases in arterial oxygenation and a decrease of the pulmonary shunt during pneumoperitoneum caused by redistribution of blood flow away from collapsed lung tissue (Strang et al., 2010). We expected that RTP would reverse the gravitational effect of abdominal content and improve arterial oxygenation. However, as reports on obese patients have shown (Sprung et al., 2002), the RTP did not have any advantage over other postures. Another possible explanation which needs to be considered is the redistribution of blood flow toward less-better ventilated lung zones along a gravitational gradient (Perilli et al., 2000) during RTP. However, further investigations are warranted.

Hemodynamic function was impaired during RTP, as most animals were hypotensive. The effect of body position on hemodynamic stability has been studied and specific changes have been observed. According to Hirvonen et al. (2000), the RTP accentuates the pneumoperitoneum-related alteration in venous return, which reduces further the preload and cardiac index. Other studies sustain an increase in the afterload during RTP via increases in MAP, systemic and pulmonary vascular resistance (Kabakchiev et al., 2018). In the present study, it was assumed that all factors affecting the cardiovascular system like mechanical ventilation with PEEP, pneumoperitoneum and head-up position have led to hypotension. This complication requires careful attention to cardiovascular state, as it can cause severe organ hypoperfusion, especially in compromised patients.

Besides the differences in compliance, PIP and MAP between body postures, the values found for each measurement were not outside of the reference intervals for rabbit (Benato et al., 2013). However, it should be pointed out that the number of the studied animals was very small and the results might not be representative for a more heterogenic population. Other limitations of this study include the absence of a control group without pneumoperitoneum for comparatively evaluation of measurements and the use of pre-set ventilator parameters (Vt and PEEP) throughout the procedure. Studies in human patients have demonstrated that total respiratory compliance changes substantially with changing the Vt and the PEEP by increasing FRC and increasing the elastance of abdominal wall (Suter et al., 1978). Although such changes could have been identified in the present study, the objective was to compare values of compliance following the course of pulmonary status during pneumoperitoneum and patient positioning. Thus, the measurements were performed at constant ventilator pattern.

\section{CONCLUSIONS}

In summary, our data suggests that pneumoperitoneum is the primary factor that alters the respiratory mechanics in rabbit patient, while the position has little effect. Although not significant differences were registered between positions, the authors of the present study consider that RTP is a more appropriate intra operative posture because may reduce the risk of lung injury risk associated with increased peak inspiratory pressure. However, careful monitoring of cardiovascular and respiratory function is needed to prevent postoperative complications.

Funding Source: This research did not receive any specific grant from funding agencies in the public, commercial, or notfor-profit sectors.

\section{Conflicts of Interest}

The authors declare that they do not have any conflict of interest.

\section{REFERENCES}

1. Benato L, Chesnel M, Eatwell K, Meredith A. Arterial blood gas parameters in pet rabbits anaesthetized using a combination of fentanyl-fluanisone-midazolam-isoflurane. Journal of Small Animal Practice. 2013; 54(7):343-6.

2. Casati A, Comotti L, Tommasino C, Leggieri C, Bignami E, Tarantino F, et al. Effects of pneumoperitoneum and reverse Trendelenburg position on cardiopulmonary function in morbidly obese patients receiving laparoscopic gastric banding. European Journal of Anaesthesiology. 2000; 17(5):300-5.

3. Davidson JT, Wasserman K, Lillington GA. Lung compliance of the rabbit and posturally induced changes in functional residual capacity. Anesthesiology. 1966; 11: 817-22. 
4. Eatwell K. Analgesia, sedation and anesthesia. In Meredith A, Lord B, editors. BSAVA Manual of rabbit medicine, $1^{\text {st }}$ ed, Uk: British Small Animal Veterinary Association, 2016; p 138-59.

5. Fahy BG, Barnas GM, Nagle SE, Flowers JL, Njoku MJ, Agarwal M. Effects of Trendelenburg and reverse Trendelenburg postures on lung and chest wall mechanics. Journal of Clinical Anaesthesia. 1996; 8(3):236-44.

6. Fletcher R, Jonson B. Deadspace and the single breath test for carbon dioxide during anaesthesia and artificial ventilation. British Journal of Anaesthesia. 1986; 56(2): 109-19.

7. Hedenstierna G, Rothen HU. Respiratory function during anaesthesia: effects on gas exchange. Comprehensive Physiology. 2012; 2(1): 69-96.

8. Hess DR. Respiratory mechanics in mechanically ventilated patients. Respiratory Care. 2014; 59(11), $1773-1794$.

9. Hirvonen EA, Poikolainen EO, Pääkkönen ME, Nuutinen LS. The adverse hemodynamic effects of anesthesia, headup tilt, and carbon dioxide pneumoperitoneum during laparoscopic cholecystectomy. Surgical Endoscopy. 2000; 14(3), 272-277.

10. Hua S, Zhang X, An S, Liu X, Feng Z. PIP, not $\mathrm{FiO}_{2}$ regulates expression of MMP-9 in the newborn rabbit VILI with different mechanical ventilation strategies. Chinese Medicine. 2013; 4(4), 137-147.

11. Ickx B, Dolomie JO, Benalouch M, Melot C, Lingier P. Arterial to End-tidal carbon dioxide tension differences in infants and children. Anaesthesia and Critical Care. 2015; 6(2): 1-4.

12. Kabakchiev C, Valverde A, Singh A, Beaufrere. Cardiovascular and respiratory effects of carbon dioxide pneumoperitoneum in the domestic rabbit (Oryctolagus cuniculus), Canadian Journal of Veterinary Research. 2020; 84 (2), 108-114.

13. Makwana DS, Patil PN, Kerketta CS, Ghogari DV, Patel BM. A comparison of $\mathrm{E}_{\mathrm{t}} \mathrm{CO}_{2}$ and $\mathrm{P}_{\mathrm{a}} \mathrm{CO}_{2}$ in laparoscopic surgery during general anesthesia. GCSMC Journal of Medical Science. 2014; 3(1): 12-15.

14. Mama K, de Rezende LM. Anesthesia management of dogs and cats for laparoscopy. In Fransson BA, Mayhwe PA, editors. Small animal laparoscopy and thoracoscopy, $1^{\text {st }}$ ed. Iowa: Wiley Blackwell, 2015; p 75-79.

15. Manner T, Aantaa R, Alanen M. Lung compliance during laparoscopic surgery in paediatric patients. Paediatric Anaesthesia. 1998; 8 (1), 25-29.

16. Mulier JPJ, Dillemans B, Van Cauwenberge S. Impact of the patient's body position on the intraabdominal workspace during laparoscopic surgery. Surgical Endoscopy. 2010; 24(6), 1398-1402.

17. Perilli V, Sollazzi L, Bozza P, Modesti C, Chierichini A, Tacchino RM et al. The effect of the reverse Trendelenburg position on respiratory mechanics and blood gases in morbidly obese patients during bariatric surgery. Anaesthesia $\&$ Analgesia. 2000; 91(6), 1520-25.

18. Petersson J, Glenny RW. Gas exchange and ventilation-perfusion relationship in the lung. European Respiratory Journal. 2014; 44(4), 1023-1041.

19. Sprung J, Whalley DG, Falcone T, Warner DO, Hubmayr RD, Hammel J. The impact of morbid obesity, pneumoperitoneum, and posture on respiratory system mechanics and oxygenation during laparoscopy. Anaesthesia \& Analgesia. 2002; 94 (5), 1345-1350.

20. Srivastava A, Niranjan A. Secrets of safe laparoscopic surgery: anaesthetic and surgical considerations. Journal of Minimal Access Surgery. 2010; 6(4), 91-94.

21. Strang CM, Freden F, Maripuu E, Hachenberg T, Hedenstierna G. Ventilation-perfusion distribution and gas exchange during carbon-dioxide pneumoperitoneum in a porcine model. British Journal of Anaesthesiology. 2010; 105 (5), 691 697.

22. Suter PM, Fairley HB, Isenberg MD. Effect of tidal volume and positive end-expiratory pressure on compliance during mechanical ventilation. Chest. 1978; 73(2), 158-162.

23. Valenza F, Chevallard G, Fossali T, Salice V, Pizzocri M, Gattinoni L. Management of mechanical ventilation during laparoscopic surgery. Best Practice \& Research Clinical Anaesthesiology. 2010; 24 (2) 227-241.

24. Walesa M, Bayat S, Albu G, Baudat A, Petak F, Habre W. Comparison between neurally-assisted, controlled, and physiologically variable ventilation in healthy rabbits. British Journal of Anaesthesia. 2018; 121(4), 918-27. 